\title{
Interaction between Spermatozoa and the Different Epithelia along the Female Reproductive Tract of
}

\section{Mustelus schmitti}

\author{
Fernanda Gabriela Elías \\ Departamento de Biología, Bioquímica y Farmacia, Universidad Nacional del Sur, Bahía Blanca, San Juan 670-8000, Argentina
}

Received: March 4, 2015 / Accepted: March 15, 2015 / Published: March 31, 2015.

\begin{abstract}
The presence of sperm was observed in different organs of the reproductive tract of $M$. schmitti. These were the club, baffle and terminal zone of the oviducal gland, posterior portion of the uterus and in the cervix. This fact allowed for consideration not only its storage but its interaction with the female reproductive tract epithelia as well. SEM (microscopic observation studies) detected loose and sole spermatozoa in the club and baffle zones in a pregnant female. On the other hand, histochemical techniques showed sperm storage tubules of the terminal zone, which contain bundles of sperm, do not stain AB (alcian blue) or PAS (periodic acid schiff). Disintegration of some of the male gametes was observed in the posterior part of the uterus with TEM (transmission electron microscopy) studies which would indicate a first uterine sperm selection. The uterine epithelial cells involved in this process showed an important level of secretion vacuoles suggesting an interaction with sperm cells. Sperm in the cervix was found without the matrix that constitutes the spermatozeugmata formed in the male tract. Some heads of the sperm were uncurled while they were interacting with the cervical cells.
\end{abstract}

Key words: Sperm, uterine epithelium, oviducal gland, chondrichthyes.

\section{Introduction}

The fate of spermatozoa within the female tract is of interest from different points of view like artificial insemination (in domestic animals and humans), to preserve DNA gametes in order to avoid extinction of species, and discover phylogenetic relationships.

Mustelus schmitti, is a small aplacental viviparous shark which distributes geografically from $22^{\circ} \mathrm{S}$, north of Rio de Janeiro (Brazil) to the south of argentinian Patagonia, $47^{\circ} 45^{\prime} \mathrm{S}$ [1-3]. The reproductive tract of this fish consists of a single left ovary, a pair of anterior oviducts, a pair of oviducal glands and paired uteri that end in a common cloaca [4]. All extant chondrichthyans have internal fertilization but develop a great variety of modes of reproduction from viviparity to oviparity $[5,6]$.

Corresponding author: Fernanda Gabriela Elías, Ph.D., research fields: reproductive biology, histology. E-mail: ferelias@criba.edu.ar.
The journey of spermatozoa into the reproductive tract of the females is a fact that occurs widely across all groups of vertebrates and this is of interest from a comparative point of view. The spermatozoa must interact with, and are altered by, their immediate biochemical environment and epithelial or immunocompetent cells [7]. Moreover, the male gametes are highly differentiated cells that every cellular compartment must not only be intact but must also respond appropriately to intracellular and extracellular signals [8].

This travel through the female tract leads to two phenomena wide spread along the whole spectrum of animals, vertebrates or invertebrates: sperm storage and multiple paternity.

Sperm storage consists in keeping the male gametes in a female reservoir in order to be ready for fertilization when the ovulation is discontinued with the mating or the chances of mating are reduced 
because of the sex segregation or other causes. Not only fish show sperm storage in special organs like oviducal glands in chondrichthyes or in ovaries like in some teleosts. Amphibians display this characteristic as well and this has been demonstrated among salamanders and caecilians. Only one frog, Ascaphus truei, with internal fertilization develops also this strategy. It is common in reptiles, birds and mammals (marsupials, bats and other eutherian mammals). As sperm storage occurs in so many diverse groups, it suggests that the adaptive advantages are considerable and for the same reason, has evolved repeatedly along the evolutionary tree [9].

If sperm storage is coupled with interspecific sperm competition and/or sperm selection from the female, it is found another factor that makes complex this scenario. It is well known that interspecific sperm competition develops as soon as the gametes are deposited in the female tract and it continues all along the way towards the fertilization. Parker et al. [10] mentioned some works of Birkhead [11, 12], where is alluded a postcopulary sexual selection as a potent agent of evolutionary diversification, generating variation in male and female behavior, morphology, physiology and biochemistry. Sperm competition depends on many factors like ejaculate volume, sperm number, sperm form, swimming speed, seminal plasma biochemistry and a varied complex interaction between the different ejaculates from competing males and finally, the interactions between each male and female in which the ejaculates compete [10].

Multiple paternity is derived from the multiple copulations that a female can make with diverse males of the same species and different spermatozoa belonging to those various males are able to fertilize many ova, giving siblings originated from more than one father. This strategy is developed by nature in a wide range of groups of vertebrates and is suggested as a mechanism by which populations may maximize genetic variability and is powerful on the direction of many evolutionary processes [13-16]. Multiple paternity is extremely common across fish group which is directly associated to parental care and mate choice [15].

Once the sperm is deposited in the female tract of $M$. schmitti, it has to travel along the various organs with different secretions what imply variety of milieu. The male gametes interact with female epithelial cells in different occasions. First, they arrive at the cervix, then continue within the uterus and finally are stored in the oviducal glands, before they reprogram their journey towards the oviduct where it is estimated the fertilization takes place.

The present study offers valuable data about reproductive biology in Chondrichthyans, especially in Mustelus genera to elucidate cellular mechanisms which play fundamental roles in fecundation in particular and reproduction in general.

\section{Materials and Methods}

\subsection{Light Microscopy}

Samples from oviducal glands and uteri were dissected, stored in Bouin overnight and then dehydrated through a series of progressively higher alcohol concentrations (70-100\%). After that, they were infiltrated in paraffin and made blocks with them.

Sections of $5 \mu \mathrm{m}$ thick were cut with a sliding microtome then affixed to glass slides. Separate sections were stained with haematoxylin and eosin, combined alcian blue and periodic acid-schiff and Masson's trichrome stain. After that, sections were mounted with Canada balsam mounting media and covered with glass microscope coverlips. Sections were photographed by a camera C7070 Olympus adapted to an Olympus BX51 light microscope.

The oviducal gland slide was scanned using a Scanner HP Scanjet 5590 L1910A and edited with Adobe Photoshop CS6.

\subsection{Transmission Electron Microscopy}

Tissue samples of uteri were first fixed in $2.5 \%$ 
glutaraldehyde in $0.5 \mathrm{M}$ cacodylate buffer ( $\mathrm{pH}$ 7.4) with $12 \%$ of sucrose [17] at $4{ }^{\circ} \mathrm{C}$, for $12 \mathrm{~h}$. The samples were subsequently washed three times with the buffer for $30 \mathrm{~min}$ each at $4{ }^{\circ} \mathrm{C}$ and then postfixed in osmium tetroxide in the same buffer, for $1 \mathrm{~h}$ at $4{ }^{\circ} \mathrm{C}$. They were dehydrated in graded ethanol $(50 \%, 70 \%$, $80 \%, 95 \%$ and three times in $100 \%$ ethanol) and infiltrated in low density resin (Spurr). The blocks of tissue were at first, sectioned at $1 \mu \mathrm{m}$ thick (semithin sections) with a Super Nova Reichert-Jung Ultra-microtome at a $90 \mathrm{~nm}$ width with a glass knife and stained in drops of $2 \%$ uranyl acetate, followed by lead citrate for $30 \mathrm{~min}$. Ultrathin sections were made at $60 \mathrm{~nm}$. Finally, each of the sections was examined and photographed (20 images each with an ES1000W Erlangshen CCD Camera, Model 785 Gatan Inc., Pleasanton, California, USA) using a JEM 1200 EX II transmission electron microscope (JEOL Ltd., Tokio, Japan) at $80 \mathrm{kV}$, belonging to the Servicio Central de Microscopía Electrónica de la Facultad de Ciencias Veterinarias, Universidad Nacional de La Plata (Argentina).

\subsection{Scanning Electron Microscopy}

Tissue samples from the oviducal gland were fixed in $2.5 \%$ glutaraldehyde in $0.5 \mathrm{M}$ cacodylate buffer (pH 7.4) with $12 \%$ of sucrose at $4{ }^{\circ} \mathrm{C}$. After the fixation, samples were washed 3 times with bidistilled water during $10 \mathrm{~min}$ each. Then, they were dehydrated through progressively higher acetone concentrations: 1 wash with acetone $25 \%$ (10 min), 1 wash with $50 \%$ and a third wash with acetone $80 \%$. Finally, the samples were dried by critical point method [18] and impregnated with gold before examination at a magnification of 350-7500X with the SEM (JEOL JSM 6360 LV).

\section{Results}

Sperm was detected in different parts of the reproductive tract of the female of $M$. schmitti. In the oviducal gland, it was found in three different zones: club, baffle and terminal. The first two zones may indicate a transitional position while the last zone was the specifically place for storage.

Sperm storage tubules of the terminal zone in the oviducal gland were detected in mature and pregnant females. There were no histological or morphological differences between the sperm stored in mature females and that present in pregnant ones. In both cases, the tubular cells of terminal zone of the oviducal gland had no affinities to PAS or AB stains (Fig. 1a). Using semithin sections the sperm storage tubules showed scarce secretion near the sperm (Fig. 1b) and TEM studies determined identical results (Fig. 1c).

Within the club zone, free spermatozoa were observed in the oviducal gland of a pregnant female (Fig. 1d). It was also observed spermatozoa in the baffle zone and in the respective tubules not attached to epithelial cells (Fig. 1d). In this case, the females caught in December (the mating season) were non pregnant and mature.

It was detected by semithin sections of electron microscopy, an interaction between uterine cells and spermatozoa in the posterior portion of the uterus of a mature female (Fig. 2a). The apical cells of the epithelium were highly vacuolated and some of them were released in the lumen where they interact with sperm. TEM studies of the same portion of the uterus determined a disintegration of some male gametes immersed in a matrix (Fig 2b; c).

Recently sperm deposited were found in the cervix and specific interaction with cervical cells was observed with an uncurled head of the male gamete (Fig 3a; b).

\section{Discussion}

The journey of the sperm through the female tract is of interest not only in fish but also in any species because elucidates what occurs in it could facilitate artificial insemination and improve knowledge in reproductive biology. Holt [19] indicates that recent 


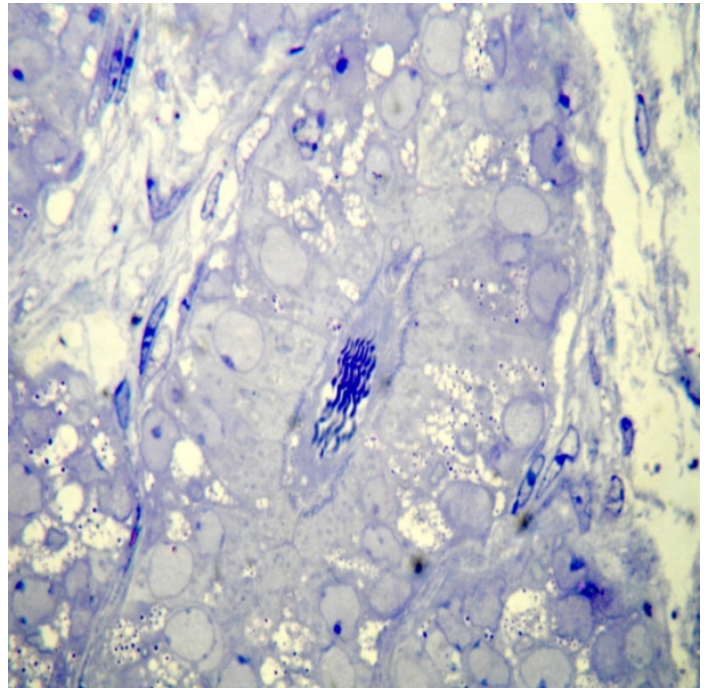

(a)

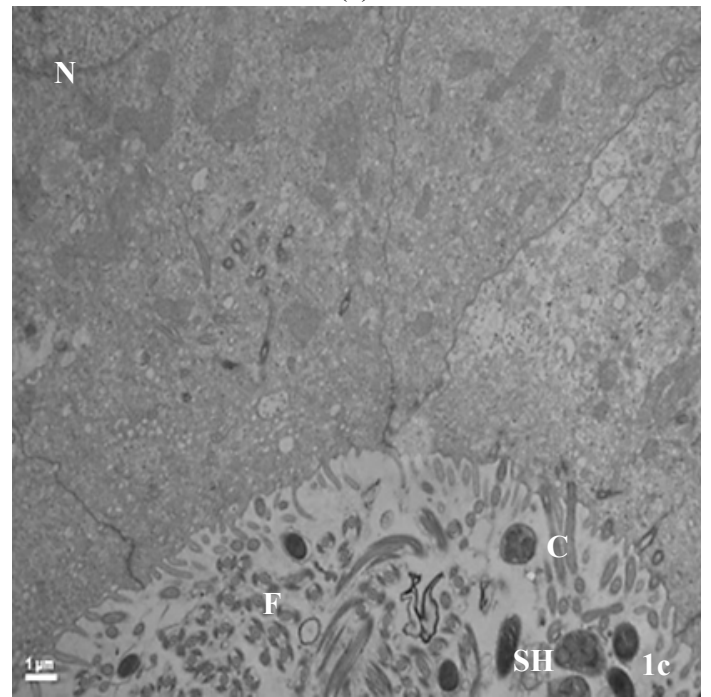

(c)

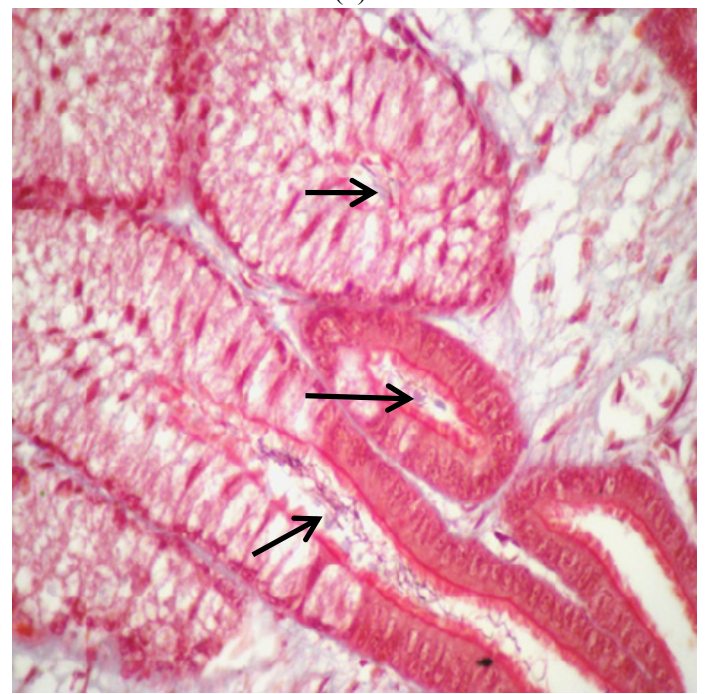

(e)

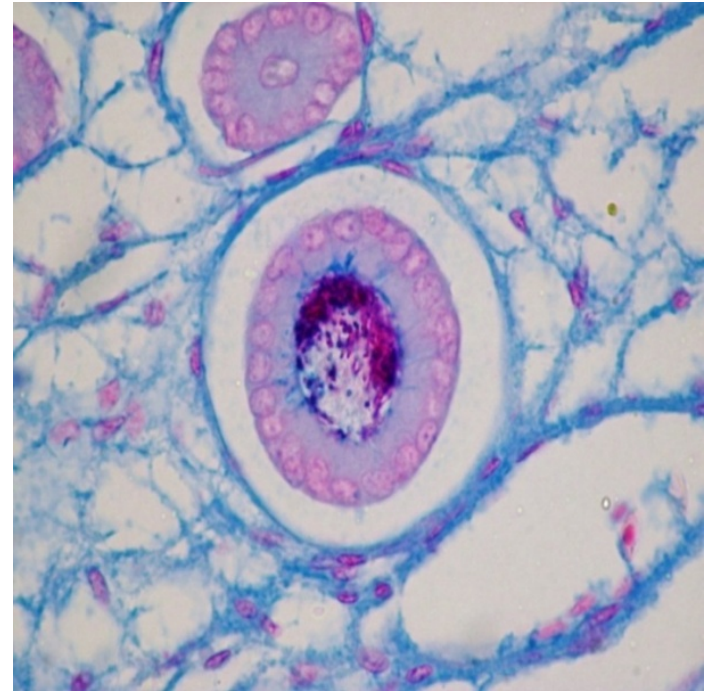

(b)

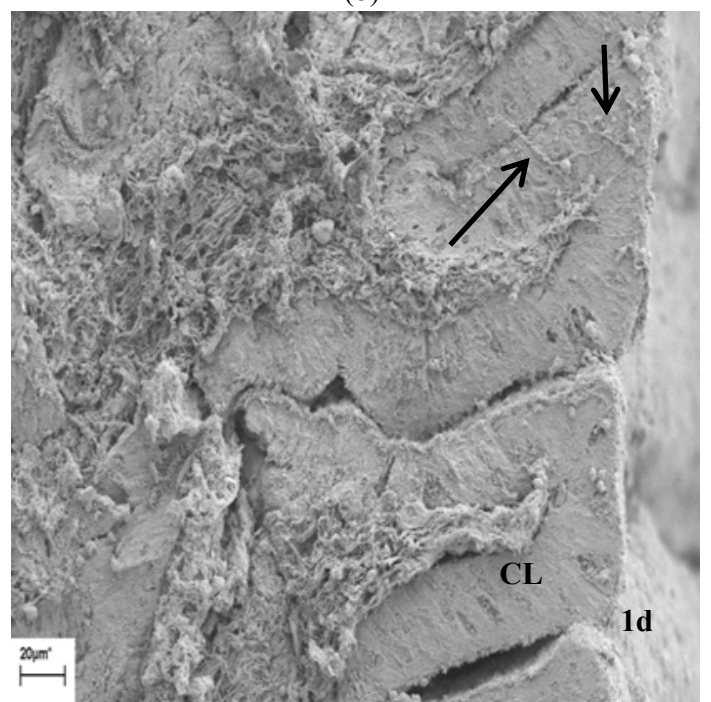

(d)

a: Sperm storage tubule with sperm. AB/PAS. 40X.

b: Sperm storage tubule in the terminal zone.

Toluidine. 100X.

c: TEM of a sperm storage tubule of the terminal zone. The sperm is embedded in a matrix. The female was pregnant.

$\mathrm{d}$ : Scanning electron micrograph of the club zone with free spermatozoon.

e: Sperm in the baffle zone (arrows). Masson. 40X.

C: Cilia; CL: Club lamella; F: Flagellum; N:

Nucleus; S: Sperm; SH: Sperm head.

Fig. 1 Presence of sperm in the oviducal gland. 

Reproductive Tract of Mustelus schmitti



(a)

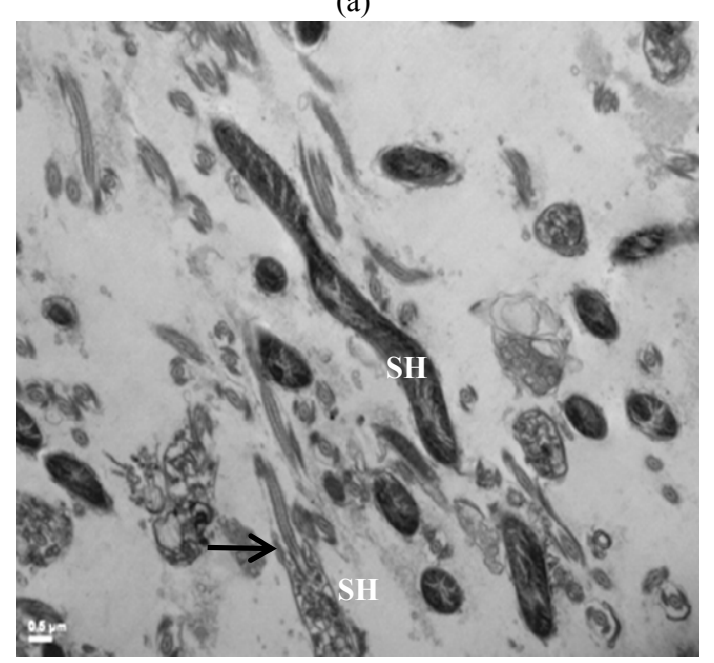

(c)

Fig. 2 Presence of sperm in the posterior portion of the uterus.



(a)

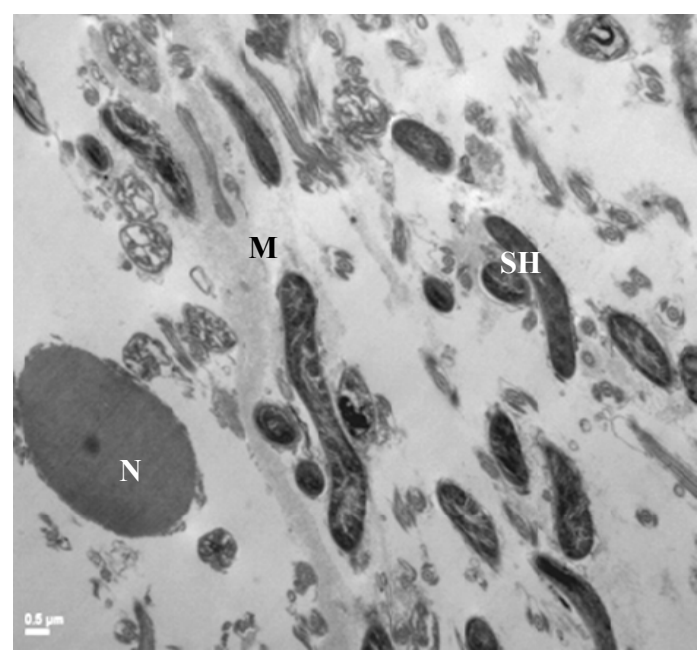

(b)

a: Semithin section of sperm interacting with uterine cells (arrows). Toluidine. 100X.

b: TEM of the sperm in the posterior region of the uterus of a mature female.

c: TEM of sperm in the posterior region of the uterus of a mature female. Note the flagellum in the disintegrated head (arrow).

N: Nucleus; M: Matrix; SH: Sperm head; UC: uterine cell.



(b)

Fig. 3 Presence of sperm in the cervix.

a: Sperm aligned in the cervix (arrows). H \& E. 20X.

b: Sperm interacting with cervical cells. Uncurled head of the sperm (arrow). H \& E. 100X.

CE: Cervical epithelium; N: Nucleus. 
studies show that spermatozoa often intimate and make chemically specific contact with epithelial cells responding by de novo gene transcription and the synthesis of new proteins. Based on the histological observations on reproductive female tract of $M$. schmitti and the data given in this work, it is proposed here that the fertilization occurs with the sperm kept in the terminal zone of the oviducal gland. Hamlett et al. [20], have proposed that spermatozoa would be previously capacitated in the uterus and would start the way up to the upper region of the oviducal glands from the sperm storage tubules even while the female is still pregnant. The time spent in the terminal zone of the oviducal gland, where the sperm is kept for some time (it is not determined yet the period of time), would maintain viable the gamete in an arrest for future pregnancies. Moreover, Chiaramonte and Petovello [2] registered two females with embryos and eggs in utero simultaneously. Apparently, it is a rare fact that occurs from time to time which may be due to an overlap in pregnancies. As no samples were obtained (yet) this comment lies in the realm of speculation, but reliable accounts from experienced fishermen during the sampling campaigns may suggest a new area of research.

In a well advanced stage of a pregnant female was found sperm running in the club zone and also in the baffle zone. On the other hand, many free spermatozoa were detected in the baffle zone in mature females ready for mating. These gametes were deep in the tubules what could suggest previous movements for fertilization. This last observation could lead to the idea that the baffle zone is another sperm reservoir [21, 22]. Upon considering these proposals the author suggests that the baffle zone may be a site where specific biochemical changes affect the sperm in its journey to the ova. This may be the reason why the sperm get deep into the tubules.

On the other hand, recent copulated females were caught and the sperm was interacting with the posterior uterus and cervix epithelia. This may show that the sperm first must be attached to the uterine cells where presumably suffer some changes in order to get ready for fertilization. Some authors detected sperm in the cervix [23], and found sperm masses in the cloaca in the $60 \%$ of females collected indicating a recent mating [24].

The attachment of the male gametes to the cervical cells in M. schmitti shows an uncurled head of the spermatozoon. As sperm rotates along their axis with little lateral tail bending [25] the straightness of the head could suggest a first selection due to the difficult in the displacement.

The male gamete needs to confront many environments since it leaves the testis.

Recent work in both freshwater and marine fish demonstrates chemical changes in the cytoplasmic membrane of the spermatozoon. In Poecilia reticulate, an ovoviviparous teleost, the spermatozoa are released in groups (spermatozeugmata) and the flagellar movements start spontaneously with the dissociation of the matrix that binds the group of gametes. This evidence shows that neither the ionic balance nor the osmolarity has effect over the hyperactivation in this species, which would suggest the existence of other mechanisms of spermatic inhibition or activation yet unknown. Tabares et al. [26], considered that the purpose of the signal cascade is to activate cellular metabolism which gives energy to the flagellum and favors its movement towards the egg.

Minakinawa and Morisawa [27] studied the spermatozoa of viviparous shark which exhibited "little motility in nonelectrolyte solution at all concentrations examined and they moved vigorously in the $\mathrm{NaCl}$ or $\mathrm{KCl}$ solution at the concentration of $500 \mathrm{mM}$ of which osmolality is $1,000 \mathrm{mOsm} / \mathrm{kg}$. Since shark sperm mixed with seawater from the siphon sac, and the uterus fluid exhibited osmolality of about $1,000 \mathrm{mOsm} / \mathrm{kg}$, it is likely that the environment with both ions and osmolality isotonic to the uterus fluid is a prerequisite for the initiation of shark sperm motility, although factors triggering it are 




Fig. 4 Spermatic sites in the reproductive tract.

Schematic representation shows the presence of sperm $(*)$ in the cervix, posterior portion of the uterus and the oviducal gland (terminal zone). Sperm located in the baffle zone $\left(^{*}\right)$.

still unclear". The same authors found the concentration of glucose in the uterus fluid was 13-fold higher than that in the seminal plasma. Furthermore, the sperm motility was kept high in the uterus fluid or blood plasma containing a high concentration of glucose whereas sperm motility sharply decreased upon dilution in the media without glucose which has the same ionic composition as the uterus fluid. These results suggest that hexose, especially glucose, has some roles for the maintenance of sperm motility in the female reproductive organ. Glucose as well as fructose is considered to be energy source for sperm motility in mammals and in viviparous fishes.

Interaction of sperm with the various portions of the female reproductive tract in $M$. schmitti has been studied analyzing structural and histological changes in many instances.

Sperm experience structural changes during the journey towards fertilization. The findings identified through this process strengthen the hypothesis that sperm undergoes interactions with epithelia and secretions with two main objectives: 1) storage and capacitation, and 2) selection, as part of the natural processes of species preservation and variability. Both objectives appear congruent with multiple paternity findings as a viable mechanism. The oviducal gland being the optimum location for storage and the uterine cyclic modifications deserve further attention of research, specifically in the biochemical contents and physiology. This may be particularly important for the development of improvements in the biological understanding of the capacitation phenomena and sperm selection.

\section{Conclusions}

The work compiles a portion of the author's Ph.D. dissertation concentrating on findings of his research and other colleagues. In this regard, the author found the presence of sperm through the length of the female reproductive tract. Also, there is considerable presence of sperm selection in the cervix and in the posterior uterine portion. Proof of this fact might be the uncurled sperm head found in the cervical zone and the uterine sperm head disintegration. A derived 
investigation of this study would be to check the sperm viability inside the oviducal gland before and during the pregnancy which might show a biological strategy to consider not only in a sustainable fishery but also in reproductive studies.

\section{References}

[1] Chiaramonte, G. E. 1998. "Shark Fisheries in Argentina." Marine and Freshwater Research 49: 747-56.

[2] Chiaramonte, G. E., and Pettovello, A. D. 2000. "The Biology of Mustelus schmitti in Southern Patagonia, Argentina." Journal of Fish Biology 57: 930-42.

[3] Massa, A., Lasta C., and Carozza, C. 2001. "Estado Actual y Explotación de Gatuzo (Mustelus schmitti) en la Plataforma Argentina." Informe Técnico N 29 del INIDEP, Mar del Plata, Argentina, 17.

[4] Elias, F. G. 2013. "Histological Features of the Reproductive Tract of the Female Mustelus schmitti. Morphological Changes and Storage of the Sperm inside the Female Tract." Ph.D. thesis, Universidad Nacional del Sur.

[5] Dulvy, N. K., and Reynolds, J. D. 1997. "Evolutionary Transitions among Egg-Laying, Live Bearing and Maternal Inputs in Sharks and Rays." Proceedings of the Royal Society of London B 264: 1309-15.

[6] Hamlett, W. C., and Koob, T. J. 1999. "Female Reproductive System. In: Sharks, Skates and Rays." In The Biology of Elasmobranch Fishes, edited by Hamlett, W. C. Baltimore: The John Hopkins University Press.

[7] Leahy, T., and Gadella, B. M. 2011. "Sperm Surface Changes and Physiological Consequences Induced by Sperm Handling and Storage." Society for Reproduction and Fertility 142: 759-78.

[8] Holt, W. V. 2009. "Is Semen Analysis Useful to Predict the Odds that the Sperm will Meet the Egg?" Reproduction in Domestic Animals 44: 31-8.

[9] Holt, W. V., and Lloyd, R. E. 2010. "Sperm Storage in the Vertebrate Female Reproductive Tract: How Does It Work so Well?" Theriogenology 73: 713-22.

[10] Parker, G. A., Immler, S., Pitnick, S., and Birkhead, T. R. 2010. "Sperm Competition Games: Sperm Size (Mass) and Number under Raffle and Displacement, and the Evolution of P2." Journal of Theoretical Biology 264: 1003-23.

[11] Birkhead, T. R., and Møller, A. P. 1998. Sperm Competition and Sexual Selection. London: Academic Press.
[12] Birkhead, T. R., Hosken, D. J., and Pitnick, S. 2009. Sperm Biology. An Evolutionary Perspective. Burlington, MA: Academic Press.

[13] Feldheim, K. A., Gruber, S. H., and Ashley, M. V. 2001. "Multiple Paternity of a Lemon Shark Litter (Chondrichthyes: Carcharhinidae)." Copeia 3: 781-6.

[14] Saville, K. J., Lindley, A. M., Maries, E. G., Carrier, J. C., and Pratt, H. L., Jr. 2002. "Multiple Paternity in the Nurse Shark, Ginglymostoma cirratum." Environmental Biology of Fishes 63: 347-51.

[15] Coleman, S. W., and Jones, A. G. 2011. "Patterns of Multiple Paternity and Maternity in Fishes." Biological Journal of the Linnean Society 103: 735-60.

[16] Veríssimo, A., Grubbs, D., McDowell, J., Musick, J., and Portnoy, D. 2011. "Frequency of Multiple Paternity in the Spiny Dogfish Squalus acanthias in the Western North Atlantic." Journal of Heredity 102: 88-93.

[17] Hyder, S. L., Cayer, M. L., and Pettey, C. L. 1983. "Cell Types in Peripheral Blood of the Nurse Shark: An Approach to Structure and Function." Tissue \& Cell 15: 437-55.

[18] Cohen, A. 1974. "Critical Point Drying". In: Principles and Techniques of Scanning Electron Microscopy, edited by Hayat. New York: Von Nostrand Reinhold.

[19] Holt, W. V. 2011. "Mechanism of Sperm Storage in the Female Reproductive Tract: An Interspecies Comparison." Reproduction in Domestic Animals 46 (Suppl.2): 68-74.

[20] Hamlett, W. C., Musick, J. A., Hysell, C. K., and Sever, D. M. 2002. "Uterine Epithelial-Sperm Interaction, Endometrial Cycle and Sperm Storage in the Terminal Zone of the Oviducal Gland in the Placental Smoothhound, Mustelus canis." Journal of Experimental Zoology 292: 129-44.

[21] Stevens, B. 2002. "Uterine and Oviducal Mechanisms for Gestation in the Common Sawshark, Pristiophorus cirratus." Thesis of Bachelor of Science. Department of Zoology. University of Melbourne, Australia.

[22] Basallo, A., Varela Junior, A. S., and Oddone, M. C. 2011. "Armazenamento de Esperma da Glândula Ovidutal da Raia ovÍpara Atlantoraja platana (Günther, 1880) (Chondrichthyes, Rajoidei)." Presented at the XIV Congreso Latino-americano de Ciencias do Mar (COLACMAR), Camboriú, Brasil.

[23] Storrie, M. T. 2004. "Microscopic Modifications of the Female Reproductive Tissues of Mustelus antarticus." Ph.D. Thesis, Deakin University.

[24] Maruska, K., Cowie, E. G., and Tricas, T. C. 1996. "Periodic Gonadal Activity and Protracted Mating in 


\section{Reproductive Tract of Mustelus schmitti}

Elasmobranch Fishes." The Journal of Experimental Zoology 276: 219-32.

[25] Hamlett, W. C. 1999. "Male Reproductive System. In: Sharks, Skates and Rays." The Biology of Elasmobranch Fishes. Baltimore: The John Hopkins University Press.

[26] Tabares, C. J., Tarazona, A. M., and Olivera Ángel, M.
2005. "Fisiología de la Activación del Espermatozoide en Peces de Agua Dulce." Revista Colombiana de Ciencias Pecuarias 18: 149-61.

[27] Minamikawa, S., and Morisawa, M. 1996. "Acquisition, Initiation and Maintenance of Sperm Motility in the Shark, Ttiakis scyllia." Comparative Biochemistry and Physiology 113A: 387-92. 